\title{
A NOVEL APPROACH TO GRAPHIC COMMUNICATION EDUCATION
}

\author{
Jure Ahtik (i), Tanja Nuša Kočevar \\ University of Ljubljana, Faculty of Natural Sciences and Engineering, Ljubljana, Slovenia
}

\begin{abstract}
Working as educators for future graphic communications experts we have to have two things in mind: how to prepare students for the real market opportunities and how to make their portfolios better. Scientific pedagogical approach was taken to do so and it is based on simulating a real-world environment: working with real world companies on real life examples, organizing students into advertising agencies where everybody has its predefined role, working in steps and competing with others. First step in our process is to divide all participants into teams of five. Each member of a team can choose his or her role: leader, designer, copywriter, speaker or technician. These roles were determined by studying different types of modern creative environments. Next step is team-building. Team has to begin working together and the final results of this cooperation is team's identity (name, logo).

First real life assignment is done with a help of real advertising agency. We invite an art director to present a brief of a real order which every group will be working on for six weeks. Each week teams get live feedback from the agency. The assignment that follows in the next six weeks is done directly for the customer. This is possible because of the experience students get when working for/with advertising agency. The final step is organizing an event, a public exhibition of work that was done in the semester.

The developed process prepares our students for the job hunting. In the paper, we explain which are the most important steps and approaches a modern educator should take to prepare their students for the real life. Results are presented as an analysis of final works, employees, co-operators and other experts in the process.
\end{abstract}

Key words: education, graphic communication, advertising, market, team work

\section{INTRODUCTION}

Generations are changing, jobs are different as they were just a few years ago. Young generations of future employees have to be prepared in a different way, as the market has different expectations.

In the field of graphic communications, design, advertising ... changes are rapid and jobs have changed a lot. In the process of education, teaching stuff has a difficult task to adopt their approach of preparing young professionals to the new world. Learning basics is as important as it ever was. Having a solid base to build on is therefore necessary. But how to build on this base? What approaches should educators take, to prepare their students to the job market? How to accomplish, that students will have some real-world experience even before they finish their education? This is the main challenge in nowadays education. Teachers therefore should be encouraged to turn focus on different types of learning processes.

In today's environment of complexity and rapid change, work is characterized by collaboration among people from variety of disciplines. Tasks for solving complex problems are too big and diverse and thus require teamwork and many kinds of expertise (Davis, 2015).

Teamwork is a context of education, where communication for learning is stimulated and consequently student-cantered experience could be purposefully achieved (Dunne et al, 2010). Benefits of teamwork in educational process are numerous. However, teamwork is not a preferable method for achieving design results for students. Therefore the instructor should emphasize the importance of teamwork skills to the students before the class and identify and underline those skills during team projects (Page et al, 2003).

\section{METHODS}

Simulating a real-world condition starts with creating a simulated advertising agency and follows with a team-building. Majority of work is done on two projects, first one with a help of a real advertising agency and the second directly to a real customer. 


\subsection{Creating a simulated advertising agency}

A team is created by joining five students. Each one gets his one role in which he or she functions until the end of the semester. These roles are:

- art director (leader of the group),

- graphic designer,

- copywriter (and lecturer),

- $\quad$ pitcher (speaker, presenter) and

- technician (problem solver).

Roles were defined by analysing jobs in advertising agencies and represent main fields of work in any graphic or communication task. Art director, graphic designer, copywriter and pitcher come directly from real life and on the market already defined jobs. Technician on the other hand, has been added as an important part when analysing work that students do. We believe, that one person, that takes the burden of solving problems as soon as they appear, makes all the other jobs much more manageable.

Students can distribute roles by themselves and they cannot be changed or rotated. The main reason is that they have to learn how to react in situations that are outside of their comfort zones, the same as in a real world. This is also manageable because a semester lasts for only 15 weeks and sticking to the same role, even if you don't like it, can be accomplished. At the end, we usually get 10 groups that are competing to the end of the semester.

\subsection{Team-building}

Second step in our novel approach is team-building - each new established team has to begin working together and each member has to begin getting used to their new role (job). We have designed this team-building as a 4-hour workshop which results in a team identity. Time limited steps in this workshop are:

1. Each member in a team writes down 10 words that describe him.

2. Papers with words are passed to other members in a group and each one deletes two words in each paper he/she gets that he/she at least agrees with.

3. At the end, group has five papers where only two word are left on each. Altogether that's 10 words on which all members in a group can agree.

4. 10 words are then connected into the short story of any kind.

5. Pitcher has to stand up and read the story out loud.

6. The following step takes the most time: based on their story, each team has to build a sculpture. Before the team-build they are all told to bring all kind of materials they would like to use, such as old packaging, colour pencils, Legos, cardboard, glue etc. Using these materials they represent their stories in a sculpture that can be very abstract. Sculptures need to stand by themselves and can be any size the team wants (Figure 1 ).

7. Sculptures are presented.

8. Teams simplify their sculptures and design logos/signs out of it.

9. Teams define names of their simulated agencies, based on stories and sculptures.

10. At the logo and team name is joined and team's identity is established (Figure 1).
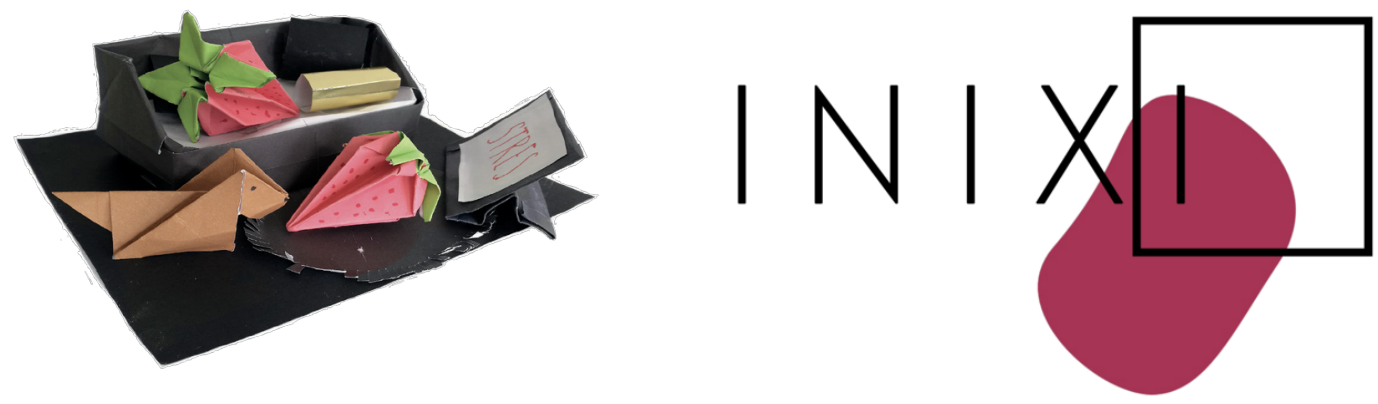

Figure 1: An example of a sculpture (left) and a final logo (right), made by team INIXI in 2018 
Two main goals are accomplished: students start to work together as a team and each team has its new graphic identity through which they communicate in the future projects.

\subsection{Working on a first project}

The first project isn't done directly to the customer, but through and with the help of an advertising agency. It all starts with an agency introduction and follows with a brief or a real customer order the agency has. The presentation is usually done by an art director who is also present on seven following lectures. Students get a weekly feedback from the lecturer and form the art director as well. The goal of a first project is to learn how a real agency works and how students should respond to their tasks, according to their given roles in their teams. At the end, students give a final presentation of their solutions and usually one of them gets picked by the agency and developed to the end with the help of authors.

Example: in 2018 we worked together with PR agency Sidera on a project for Huawei Slovenija. The goal was to make Slovenian inspired EMUI themes for Huawei mobile phones. Eight of this themes are now available on EMUI theme store (Figure 2).
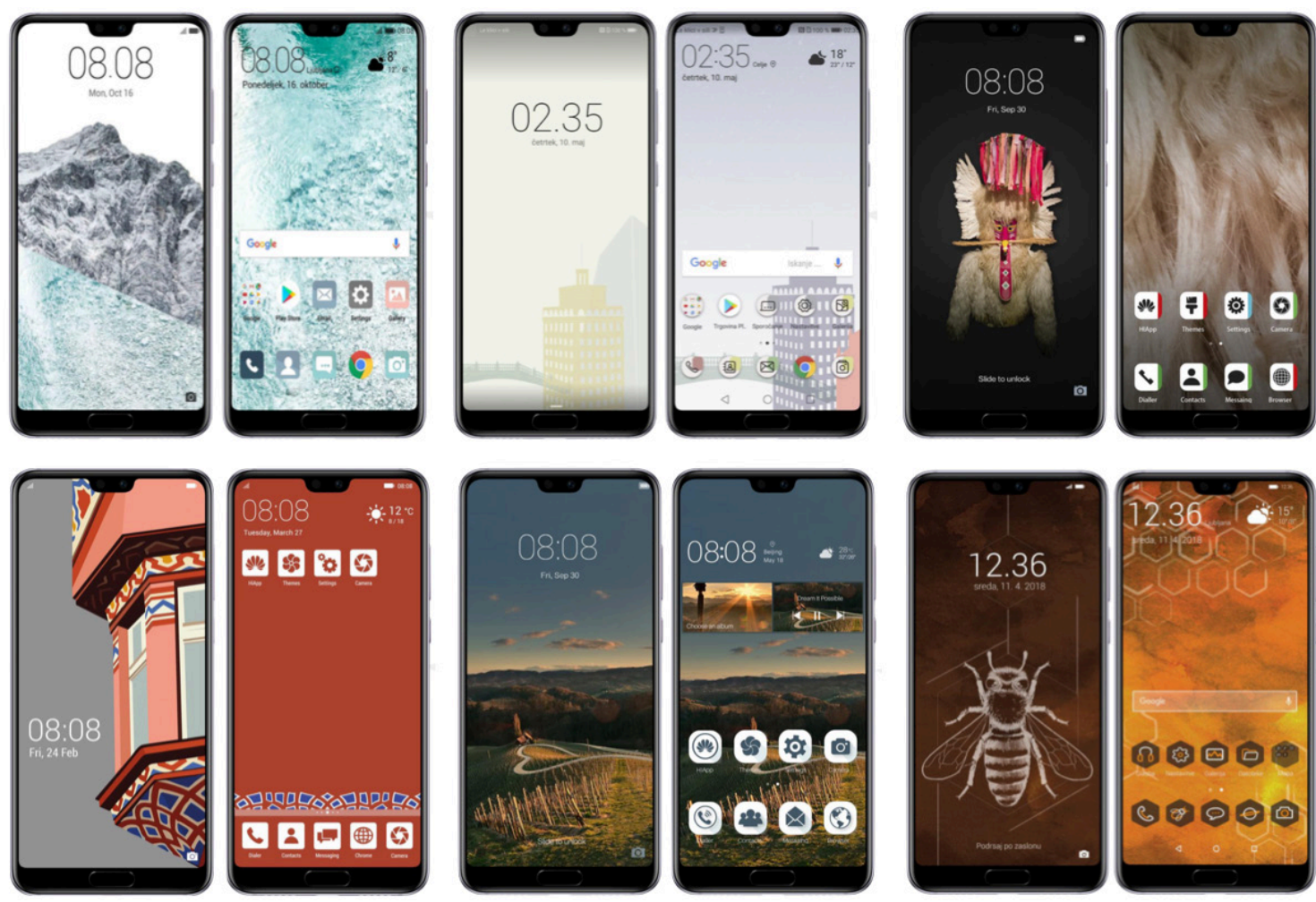

Figure 2: Few of the EMIU themes designed by the students as their first project

\subsection{Working on a second project}

The first project gives students some knowledge about the design process which is the base for the second project. The second project again starts with a design brief, presented directly by the customer, not the agency. Teams have seven weeks to complete the brief's goals. Weekly feedbacks and lectures support students' work, but mostly they work independently. Therefore students and lecturers have to take more responsibility for project development, from conception to completion, because there is no help from the advertising agency. Goals have to be completed, no matter what. Second project ends with a public exhibition.

Important note to that is, that students have to learn how to trust their own creativity and to become strong and self-conscious individuals who will be able to go out there and find a job that they prefer.

Example: in 2018 we worked directly with the Basketball association of Slovenian on promoting the world cup qualifying games for the Slovenian national basketball team (current European champions). Billboards and online advertising based on the winning visual identity are still being used at this moment (Figure 3 ). 

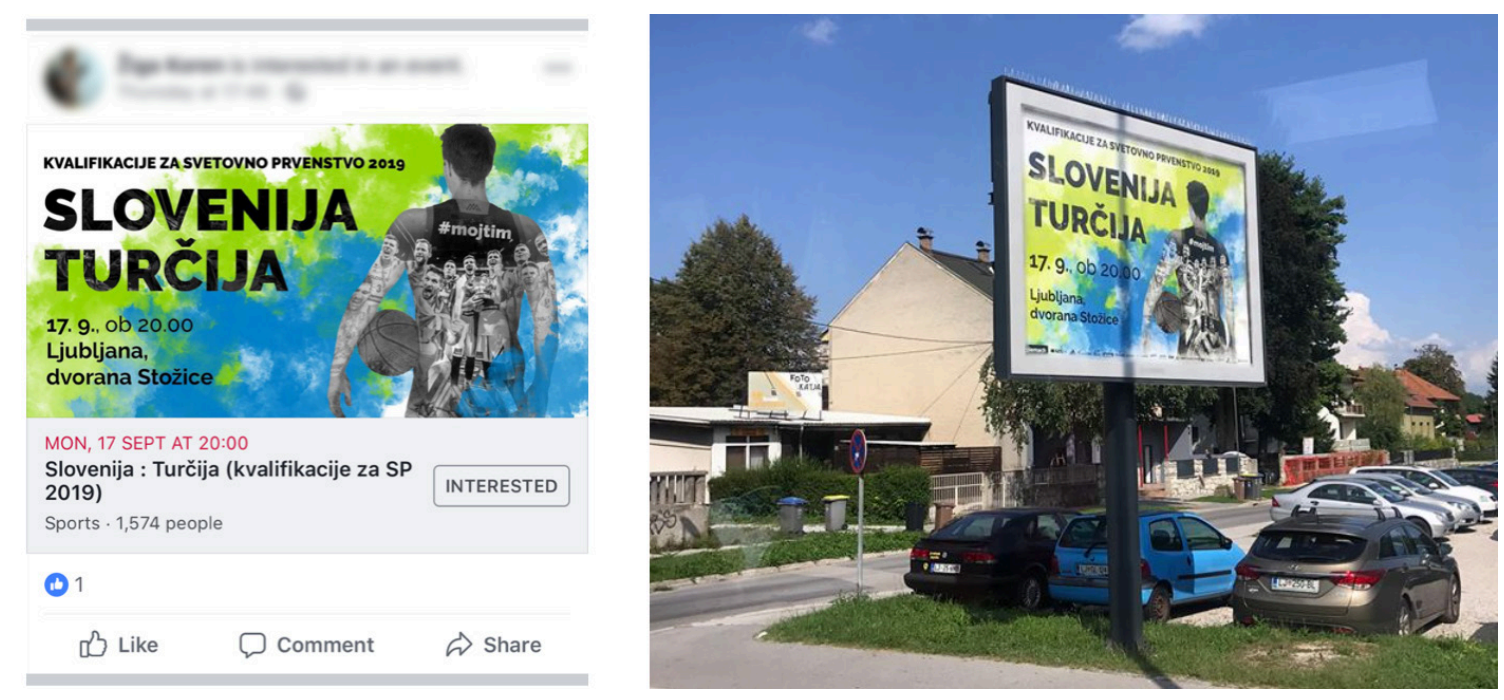

Figure 3: Facebook advertisement (left) and billboard with a winning visual identity

\subsection{Creative process}

When we work on both real-world projects, the creative process is divided into several stages:

1. Research: students have to understand a market that a customer is working on, to know competition and to be aware of target groups.

2. Analysis or redefinition: students have to understand customers' communication solutions and how they are using them.

3. Outline and construction: first step in constructing the solution is to apply rules, primary graphic elements and basic designs.

4. Application and design: students define final communication elements, such as logo, typography, colours, secondary elements, etc.

5. Production: based on application and design, all communication media is prepared.

6. Usage: the final stage is not done by students but by a customer. An important thing of this final stage is that an author is able to step out of the usage and that a customer is able to communicate by himself.

\subsection{Using ICT}

In the process of managing the described approach to graphic communication education, there is a lot of communication and task management that has to be done. Using information and communications technology (ICT) is a proposed and well established way of engaging students and lecturers to communicate. In the creative process there is usually a big amount of data that needs to be transferred between different parties and using cloud based solution has proven to be the most useful way to do it. It is also important to archive all history of changes that has been done to developing products. In our novel approach to education we use ICT for (Bouarab-Dahmani et al, 2015; Hamiti et al, 2014; Digitalna Slovenija 2020, 2016):

- communication (e-mail and other messaging tools, such as Google Talk or Discord),

- data sharing and commenting (cloud based storage, such as Google Drive or Dropbox),

- $\quad$ archiving (cloud based storage, such as Google Drive or Dropbox).

\section{RESULTS}

Students, who attended the course the last three years, were asked to deliver critical evaluation of the course by answering the online research questionnaire. Some of the students still study and some of them already have a job. The encompassed questions were qualitative as well as quantitative. Majority of questions asked students to specify their level of agreement or disagreement on a Likert scale (1-5), where 5 means that they totally agree and 1 means that they totally disagree. In some cases students could pick one from the given answers and there were also some questions where students could 
response in a descriptive manner. 53 students filled out the questionnaire. The questions covered the following topics:

- general questions,

- course enrolment examination,

- team work,

- project work,

- general contentment with the course.

In the general part of the questionnaire students were asked to explain why they chose the course. The majority of them mentioned the positive recommendation of students from previous years as a motive. Many students selected the course because they like to design in general or they wanted to work with real clients and agencies. Those students want to build their career as graphic designers. Some of them were motivated by the interesting presentation of the course and some students wanted to challenge themselves in a team work. One of the students wrote that the reason for choosing the course was the fact that there is no written exam.

Too many students want to join the Media visualization course each academic year. With the aim to perform a quality course work, we decided to limit the enrolment with the enrolment examination. 50 students $(95,3 \%)$ confirmed the examination as an appropriate method for enrolment limitation, and 23 students (52,3\%) approved the content of the examination assignment.

Students predominantly have good opinion on team work. 25 students $(47,2 \%)$ valued team work as very good and only one student (1,9\%) as very bad. $34(64,2 \%)$ students established that their role in the team was appropriate, what shows that preliminary decisions about their work and estimation about their competences were correct.

Answers about the team composition revealed that group members did not perceive two roles as very important, these are the role of a pitcher (speaker, presenter) and the role of a technician (problem solver). Most of the students evaluated the two mentioned roles as important (level 4), for the pitcher 20 students (37,7\%) and for the technician 19 students (35,8\%). These two roles were also the only ones that were evaluated as not important at all by a few students, the pitcher by $3(5,7) \%)$ and the technician by $4(7,5 \%)$.

The questionnaire also enclosed questions about the guided team building that was performed at the beginning of the course. 28 students $(52,8 \%)$ answered that it was very important for creation of a team's identity and nobody valued that it wasn't important at all. 24 students (45,3\%) estimated that the team building was very important for further work of the team, but 5 students answered that it was not important ( 2 students chose option 1 and 3 students chose option 2 on the 1-5 scale).

Students also wrote some suggestions; draw of the team members, the possibility to change the role in the team and to have more designers in the group.

Project work was the next part of questionnaire. 30 students $(56,6 \%)$ evaluated presentations and the overall role of the agency's representative on the course very important. 5 of them $(9,4 \%)$ had neutral and 2 of them $(3,8 \%)$ had negative opinion.

Having weekly presentations, student could accompany other students work. 26 students $(49,1 \%)$ strongly agreed with that, 9 students (17\%) were neutral and 3 students $(5,7 \%)$ disagreed. Very similar is students' opinion on weekly reviews of their work. $54,7 \%$ of them thought that they are important and $69,8 \%$ of them believed that there was enough time for them each week. $28,3 \%$ of students would like to have more time for reviews.

Student were asked for their opinion about lectures. Some of them would like to learn even more from agency representatives while they appreciated their opinion and their reviews.

In the conclusion, 28 (52,8 \%) students strongly agreed that they improved their teamwork competence. $34(64,2 \%)$ students think that the course extensively influenced the project realization capabilities in the field of media communications, and $27(50,9 \%)$ thought that the course definitely influenced their critical relations to their own works.

A little smaller percent of students $(43,4 \%)$ strongly agreed that they improved their presentation skills, $28 \%$ agree and $22,6 \%$ are neutral. Only 2 students (3,8 \%) strongly disagreed and 1 student $(1,9 \%)$ disagreed with the statement mentioned above.

One of the last question was "Do you think that the course improved your employment possibilities?" 15 students $(28,3 \%)$ thought that their employment possibilities strongly improved, 22 students answered that the possibilities improved, 13 students were neutral, 2 students disagreed and only 1 student strongly disagreed with that. 


\section{DISCUSSION}

According to the results where the students' opinion on the course are presented, we can establish that the course meets the students' initial expectations. However, the survey reveals some interesting suggestions and opinions we are going to consider in the future, such as:

- adjusting roles in each team to distribute the amount of work more equally,

- changing the content of the enrollment exam and

- $\quad$ inviting more real-world lecturers/experts into the course.

Through the whole process mentors evaluated actual results as well as student's individual progress respectively subject-specific competencies.

\section{CONCLUSIONS}

Simulating a real-world environment has proven to be a useful way of educating a future graphic communications professional. We strongly believe, that students, educated by our approach, have more work experiences and better portfolios to show to their future employees. An important goal that we have accomplished with our approach is that we are able to show students, how does advertising industry look and feel like and to help them decide if this really is something they would like to do. In the future, we are planning to use and develop this novel approach on post graduate study program (beginning in 2018/19 academic year). We have also began testing the approach on smaller groups of students and more targeted projects what also shows very good results.

Working with real agencies we would like to teach students other skills too, such as negotiating and selling ideas, maintain schedules, appreciate deadlines, and with introducing the teamwork, we would like to demonstrate the experience of working in an industry with people of diverse ideas, abilities, opinions and noteworthy, various routines.

\section{ACKNOWLEDGMENTS}

We would like to thank the following advertising and PR agencies that trusted and helped us develop our education approach: Yin+Young, Agencija 101, Sidera and Rubikon GRAL.

\section{REFERENCES}

[1] Bouarab-Dahmani, F., Tahi, R.: "New Horizons on Education Inspired by Information and Communication Technologies", Procedia - Social and Behavioral Sciences 174, 602-608, 2015. doi: $10.1016 / j . s b s p r o .2015 .01 .589$.

[2] Davis, M.: "Interdisciplinarity and the Education of the Design Generalist", The Education of a Graphic Designer (Allworth Press, New York, 2015).

[3] Digitalna Slovenija, Digitalna Slovenija 2020, Strategija razvoja informacijske družbe do leta 2020, Digitalna Slovenija, 2016, URL: http://www.mju.gov.si/fileadmin/mju.gov.si/pageuploads/DID/Informacijska_druzba/DSI_2020.pdf (last request: 2018-06-21).

[4] Dunne, E., Rawlins, M.: "Bridging the Gap Between Industry and Higher Education: Training Academics to Promote Student Teamwork", Innovations in Education and Training International 37(4), 361-371, 2010. doi: 10.1080/135580000750052973.

[5] Hamiti, M., Reka, B., Baloghová, A.: "Ethical Use of Information Technology in High Education", Procedia - Social and Behavioral Sciences 116, 4411-4415, 2014. doi:10.1016/j.sbspro.2014.01.957.

[6] Page, D., Donelan, J. G.: "Team-Building Tools for Students", Journal of Education for Business 78(3), 125-128, 2013. doi: 10.1080/08832320309599708. 


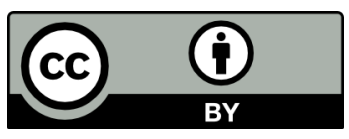

(C) 2018 Authors. Published by the University of Novi Sad, Faculty of Technical Sciences, Department of Graphic Engineering and Design. This article is an open access article distributed under the terms and conditions of the Creative Commons Attribution license 3.0 Serbia

(http://creativecommons.org/licenses/by/3.0/rs/). 